Lecture Notes in Electrical Engineering 365

Felix Pasila

Yusak Tanoto

Resmana Lim

Murtiyanto Santoso

Nemuel Daniel Pah

Editors

Proceedings of Second International Conference on Electrical Systems, Technology and Information 2015 (ICESTI 2015) 


\section{Lecture Notes in Electrical Engineering}

\section{Volume 365}

\section{Board of Series editors}

Leopoldo Angrisani, Napoli, Italy

Marco Arteaga, Coyoacán, México

Samarjit Chakraborty, München, Germany

Jiming Chen, Hangzhou, P.R. China

Tan Kay Chen, Singapore, Singapore

Rüdiger Dillmann, Karlsruhe, Germany

Haibin Duan, Beijing, China

Gianluigi Ferrari, Parma, Italy

Manuel Ferre, Madrid, Spain

Sandra Hirche, München, Germany

Faryar Jabbari, Irvine, USA

Janusz Kacprzyk, Warsaw, Poland

Alaa Khamis, New Cairo City, Egypt

Torsten Kroeger, Stanford, USA

Tan Cher Ming, Singapore, Singapore

Wolfgang Minker, Ulm, Germany

Pradeep Misra, Dayton, USA

Sebastian Möller, Berlin, Germany

Subhas Mukhopadyay, Palmerston, New Zealand

Cun-Zheng Ning, Tempe, USA

Toyoaki Nishida, Sakyo-ku, Japan

Bijaya Ketan Panigrahi, New Delhi, India

Federica Pascucci, Roma, Italy

Tariq Samad, Minneapolis, USA

Gan Woon Seng, Nanyang Avenue, Singapore

Germano Veiga, Porto, Portugal

Haitao Wu, Beijing, China

Junjie James Zhang, Charlotte, USA 
"Lecture Notes in Electrical Engineering (LNEE)" is a book series which reports the latest research and developments in Electrical Engineering, namely:

- Communication, Networks, and Information Theory

- Computer Engineering

- Signal, Image, Speech and Information Processing

- Circuits and Systems

- Bioengineering

LNEE publishes authored monographs and contributed volumes which present cutting edge research information as well as new perspectives on classical fields, while maintaining Springer's high standards of academic excellence. Also considered for publication are lecture materials, proceedings, and other related materials of exceptionally high quality and interest. The subject matter should be original and timely, reporting the latest research and developments in all areas of electrical engineering.

The audience for the books in LNEE consists of advanced level students, researchers, and industry professionals working at the forefront of their fields. Much like Springer's other Lecture Notes series, LNEE will be distributed through Springer's print and electronic publishing channels.

More information about this series at http://www.springer.com/series/7818 
Felix Pasila $\cdot$ Yusak Tanoto

Resmana Lim - Murtiyanto Santoso

Nemuel Daniel Pah

Editors

Proceedings of Second

International Conference

on Electrical Systems,

Technology and Information

2015 (ICESTI 2015)

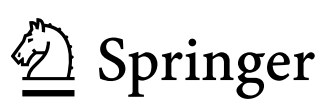




\section{Editors}

Felix Pasila

Department of Electrical Engineering

Petra Christian University

Surabaya

Indonesia

Yusak Tanoto

Department of Electrical Engineering

Petra Christian University

Surabaya

Indonesia

Resmana Lim

Department of Electrical Engineering

Petra Christian University

Surabaya

Indonesia

\author{
Murtiyanto Santoso \\ Department of Electrical Engineering \\ Petra Christian University \\ Surabaya \\ Indonesia
}

Nemuel Daniel Pah

University of Surabaya

Surabaya

Indonesia

ISSN 1876-1100

ISSN 1876-1119 (electronic)

Lecture Notes in Electrical Engineering

ISBN 978-981-287-986-8

ISBN 978-981-287-988-2 (eBook)

DOI 10.1007/978-981-287-988-2

\section{Library of Congress Control Number: 2015960766}

(C) Springer Science+Business Media Singapore 2016

This work is subject to copyright. All rights are reserved by the Publisher, whether the whole or part of the material is concerned, specifically the rights of translation, reprinting, reuse of illustrations, recitation, broadcasting, reproduction on microfilms or in any other physical way, and transmission or information storage and retrieval, electronic adaptation, computer software, or by similar or dissimilar methodology now known or hereafter developed.

The use of general descriptive names, registered names, trademarks, service marks, etc. in this publication does not imply, even in the absence of a specific statement, that such names are exempt from the relevant protective laws and regulations and therefore free for general use.

The publisher, the authors and the editors are safe to assume that the advice and information in this book are believed to be true and accurate at the date of publication. Neither the publisher nor the authors or the editors give a warranty, express or implied, with respect to the material contained herein or for any errors or omissions that may have been made.

Printed on acid-free paper

This Springer imprint is published by SpringerNature

The registered company is Springer Science+Business Media Singapore Pte Ltd. 


\section{Contents}

\section{Part I Invited Speaker}

1 Computational Intelligence Based Regulation of the DC Bus in the On-grid Photovoltaic System . . . . . . . . . . . . 3

Mauridhi Hery Purnomo, Iwan Setiawan and Ardyono Priyadi

2 Virtual Prototyping of a Compliant Spindle for Robotic Deburring . . . . . . . . . . . . . . . . . . . . . . . . . . . . 17

Giovanni Berselli, Marcello Pellicciari, Gabriele Bigi and Angelo O. Andrisano

3 A Concept of Multi Rough Sets Defined on Multi-contextual Information Systems. Rolly Intan

Part II Technology Innovation in Robotics Image Recognition and Computational Intelligence Applications

4 Coordinates Modelling of the Discrete Hexapod Manipulator via Artificial Intelligence.

Felix Pasila and Roche Alimin

5 An Object Recognition in Video Image Using Computer

Vision

Sang-gu Kim, Seung-hoon Kang, Joung Gyu Lee and Hoon Jae Lee

6 Comparative Study on Mammogram Image Enhancement Methods According to the Determinant of Radiography Image Quality .

Erna Alimudin, Hanung Adi Nugroho and Teguh Bharata Adji 
7 Clustering and Principal Feature Selection Impact

for Internet Traffic Classification Using K-NN . . . . . . . . . . . . 75

Trianggoro Wiradinata and P. Adi Suryaputra

8 Altitude Lock Capability Benchmarking: Type 2 Fuzzy, Type 1 Fuzzy, and Fuzzy-PID with Extreme Altitude

Change as a Disturbance . . . . . . . . . . . . . . . . 83

Hendi Wicaksono, Yohanes Gunawan, Cornelius Kristanto

and Leonardie Haryanto

9 Indonesian Dynamic Sign Language Recognition at Complex

Background with 2D Convolutional Neural Networks . . . . . . . . . 91

Nehemia Sugianto and Elizabeth Irenne Yuwono

10 Image-Based Distance Change Identification by Segment

Correlation . . . . . . . . . . . . . . . . . . . . . 99

Nemuel Daniel Pah

11 Situation Awareness Assessment Mechanism

for a Telepresence Robot . . . . . . . . . . . . . . . . . . . . . . . 107

Petrus Santoso and Handry Khoswanto

12 Relevant Features for Classification of Digital Mammogram

Images. . . . . . . . . . . . . . . . . . . . . . . . 115

Erna Alimudin, Hanung Adi Nugroho and Teguh Bharata Adji

13 Multi-objective Using NSGA-2 for Enhancing

the Consistency-Matrix.

Abba Suganda Girsang, Sfenrianto and Jarot S. Suroso

14 Optimization of AI Tactic in Action-RPG Game . . . . . . . . . . . . 131

Kristo Radion Purba

15 Direction and Semantic Features for Handwritten Balinese

Character Recognition System

Luh Putu Ayu Prapitasari and Komang Budiarta

16 Energy Decomposition Model Using Takagi-Sugeno

Neuro Fuzzy

Yusak Tanoto and Felix Pasila

17 Odometry Algorithm with Obstacle Avoidance

on Mobile Robot Navigation.

Handry Khoswanto, Petrus Santoso and Resmana Lim 
Part III Technology Innovation in Electrical Engineering, Electric Vehicle and Energy Management

18 Vision-Based Human Position Estimation and Following Using an Unmanned Hexarotor Helicopter . . . . . . . . . . . . . 165 Jung Hyun Lee and Taeseok Jin

19 The Role of Renewable Energy: Sumba Iconic Island, an Implementation of 100 Percent Renewable Energy by 2020 . . . . . 173 Abraham Lomi

20 Electromechanical Characterization of Bucky Gel Actuator Based on Polymer Composite PCL-PU-CNT for Artificial Muscle . . . . . . . . . . . . . . . . . . . . . . 185 Yudan Whulanza, Andika Praditya Hadiputra, Felix Pasila and Sugeng Supriadi

21 A Single-Phase Twin-Buck Inverter . . . . . . . . . . . . . . . . . 193 Hanny H. Tumbelaka

22 Performance Comparison of Intelligent Control of Maximum Power Point Tracking in Photovoltaic System. . . . . . . . . . . . . . . . . . . . . . . . . 203 Daniel Martomanggolo Wonohadidjojo

23 Vehicle Security and Management System on GPS Assisted Vehicle Using Geofence and Google Map Lanny Agustine, Egber Pangaliela and Hartono Pranjoto

24 Security and Stability Improvement of Power System Due to Interconnection of DG to the Grid .

Ni Putu Agustini, Lauhil Mahfudz Hayusman, Taufik Hidayat and I. Made Wartana

25 Solar Simulator Using Halogen Lamp for PV Research . . . . . . . . 239 Aryuanto Soetedjo, Yusuf Ismail Nakhoda, Abraham Lomi and Teguh Adi Suryanto

26 Artificial Bee Colony Algorithm for Optimal Power Flow on Transient Stability of Java-Bali $500 \mathrm{KV}$.

Irrine Budi Sulistiawati and M. Ibrahim Ashari

27 Sizing and Costs Implications of Long-Term Electricity Planning: A Case of Kupang City, Indonesia.

Daniel Rohi and Yusak Tanoto

28 Dynamic Simulation of Wheel Drive and Suspension System in a Through-the-Road Parallel Hybrid Electric Vehicle . . . . . . . 263 Mohamad Yamin, Cokorda P. Mahandari and Rasyid H. Sudono 
29 A Reliable, Low-Cost, and Low-Power Base Platform for Energy Management System . . . . . . . . . . . . . . . . . 271

Henry Hermawan, Edward Oesnawi and Albert Darmaliputra

30 Android Application for Distribution Switchboard Design . . . . . . 279 Julius Sentosa Setiadji, Kevin Budihargono and Petrus Santoso

Part IV Technology Innovation in Electronic, Manufacturing, Instrumentation and Material Engineering

31 Adaptive Bilateral Filter for Infrared Small Target Enhancement .

Tae Wuk Bae and Hwi Gang Kim

32 Innovative Tester for Underwater Locator Beacon Used in Flight/Voyage Recorder (Black Box) . . . . . . . . . . . . . . . . 299 Hartono Pranjoto and Sutoyo

33 2D CFD Model of Blunt NACA 0018 at High Reynolds Number for Improving Vertical Axis Turbine Performance . . . . . . 309 $\mathrm{Nu}$ Rhahida Arini, Stephen R. Turnock and Mingyi Tan

34 Recycling of the Ash Waste by Electric Plasma Treatment to Produce Fibrous Materials

S.L. Buyantuev, A.S. Kondratenko, E.T. Bazarsadaev and A.B. Khmelev

35 Performance Evaluation of Welded Knitted E-Fabrics for Electrical Resistance Heating.

Senem Kursun Bahadir, Ozgur Atalay, Fatma Kalaoglu, Savvas Vassiliadis and Stelios Potirakis

36 IP Based Module for Building Automation System

J.D. Irawan, S. Prasetio and S.A. Wibowo

37 Influence of CTAB and Sonication on Nickel Hydroxide Nanoparticles Synthesis by Electrolysis at High Voltage. . . . . . . . 345 Yanatra Budipramana, Suprapto, Taslim Ersam and Fredy Kurniawan

38 Waste Industrial Processing of Boron-Treated by Plasma Arc to Produce the Melt and Fiber Materials

S.L. Buyantuev, Ning Guiling, A.S. Kondratenko, Junwei Ye,

E.T. Bazarsadaev, A.B. Khmelev and Shuhong Guo

39 Design of Arrhythmia Detection Device Based on Fingertip

Pulse Sensor

R. Wahyu Kusuma, R. Al Aziz Abbie and Purnawarman Musa 
40 Analysis of Fundamental Frequency and Formant Frequency for Speaker 'Makhraj' Pronunciation with DTW Method . . . . . . . 373 Muhammad Subali, Miftah Andriansyah and Christanto Sinambela

41 Design and Fabrication of "Ha (Un)" Shape-Slot Microstrip Antenna for WLAN $2.4 \mathbf{G H z} \ldots \ldots \ldots \ldots 383$ Srisanto Sotyohadi, Sholeh Hadi Pramono and Moechammad Sarosa

42 Investigation of the Electric Discharge Machining on the Stability of Coal-Water Slurries . . . . . . . . . . . . . . . . 393 S.L. Buyantuev, A.B. Khmelev, A.S. Kondratenko and F.P. Baldynova

43 A River Water Level Monitoring System Using Android-Based Wireless Sensor Networks for a Flood Early Warning System . . . . 401 Riny Sulistyowati, Hari Agus Sujono and Ahmad Khamdi Musthofa

44 The Influence of Depth of Cut, Feed Rate and Step-Over on Surface Roughness of Polycarbonate Material in Subtractive Rapid Prototyping

The Jaya Suteja

45 Adaptive Cars Headlamps System with Image Processing and Lighting Angle Control .

William Tandy Prasetyo, Petrus Santoso and Resmana Lim

46 Changes in the Rheological Properties and the Selection of a Mathematical Model of the Behavior of Coal-Water Slurry During Transport and Storage. . . . . . . . . . . . . . . . 423 S.L. Buyantuev, A.B. Khmelev and A.S. Kondratenko

47 Design of a Fetal Heartbeat Detector.

Nur Sultan Salahuddin, Sri Poernomo Sari, Paulus A. Jambormias and Johan Harlan

Part V Technology Innovation in Internet of Things and Its Applications

48 Network Traffic and Security Event Collecting System Hee-Seung Son, Jin-Heung Lee, Tae-Yong Kim and Sang-Gon Lee

49 Paper Prototyping for BatiKids: A Technique to Examine Children's Interaction and Feedback in Designing a Game-Based Learning . 
50 Tracing Related Scientific Papers by a Given Seed

Paper Using Parscit . . . . . . . . . . . . . . . . . . . . . . . . . 457

Resmana Lim, Indra Ruslan, Hansin Susatya, Adi Wibowo,

Andreas Handojo and Raymond Sutjiadi

51 Factors Affecting Edmodo Adoption as Online Learning

Medium . . . . . . . . . . . . . . . . . . . . . . . . . . . 465

Iwa Sungkono Herlambangkoro and Trianggoro Wiradinata

52 Principal Feature Selection Impact for Internet Traffic

Classification Using Naïve Bayes . . . . . . . . . . . . . . . . . . . . . . 475

Adi Suryaputra Paramita

53 Study on the Public Sector Information (PSI) Service Model

for Science and Technology Domain in South Korea . . . . . . . . . . . 481

Yong Ho Lee

54 Digital Natives: Its Characteristics and Challenge

to the Library Service Quality . . . . . . . . . . . . . . . . . . . . . . . . 487

Siana Halim, Felecia, Inggrid, Dian Wulandari

and Demmy Kasih

55 Web-Based Design of the Regional Health Service System

in Bogor Regency.

B. Sundari, Revida Iriana and Bertilia Lina Kusrina

56 Security Handwritten Documents Using Inner Product . . . . . . . . 501 Syaifudin and Dian Pratiwi

57 Augmented Reality Technique for Climate Change Mitigation . . . . 511 Ruswandi Tahrir

58 Cyber Security for Website of Technology Policy Laboratory . . . . 521 Jarot S. Suroso

59 TAM-MOA Hybrid Model to Analyze the Acceptance of Smartphone for Pediatricians in Teaching Hospital in Indonesia.

Oktri Mohammad Firdaus, Nanan Sekarwana,

T.M.A. Ari Samadhi and Kah Hin Chai

60 Development of the Remote Instrumentation Systems

Based on Embedded Web to Support Remote Laboratory . . . . . . 537

F. Yudi Limpraptono and Irmalia Suryani Faradisa

61 Enhancing University Library Services with Mobile Library Information System . . . . . . . . . . . . . . . . . . . . . . . . . . . 545

Singgih Lukman Anggana and Stephanus Eko Wahyudi 
62 Multi Level Filtering to Classify and Block Undesirable Explicit Material in Website .

Mohammad Iqbal, Hifshan Riesvicky, Hasma Rasjid and Yulia Charli

63 Query Rewriting and Corpus of Semantic Similarity as Encryption Method for Documents in Indonesian Language. . 565

Detty Purnamasari, Rini Arianty, Diana Tri Susetianingtias and Reni Diah Kusumawati

64 Securing Client-Server Application Design for Information System Inventory . . . . . . . . . . . . . . . . . . . . . . . . 573 Ibnu Gunawan, Djoni Haryadi Setiabudi, Agustinus Noertjahyana and Yongky Hermawan

Part VI Technology Innovation in Information, Modelling and Mobile Applications

65 Analyzing Humanitarian Logistic Coordination

for Disaster Relief in Indonesia.

Tanti Octavia, I. Gede Agus Widyadana and Herry Christian Palit

66 Surakarta Cultural Heritage Management Based on Geographic Information Systems

Ery Dewayani and M. Viny Christanti

67 Gray Code of Generating Tree of $\boldsymbol{n}$ Permutation with $\boldsymbol{m}$ Cycles

Sulistyo Puspitodjati, Henny Widowati and Crispina Pardede

68 Android and iOS Hybrid Applications for Surabaya Public Transport Information

Djoni Haryadi Setiabudi and Lady Joanne Tjahyana

69 Games and Multimedia Implementation on Heroic Battle of Surabaya: An Android Based Mobile Device Application.

Andreas Handojo, Resmana Lim, Justinus Andjarwirawan and Sandy Sunaryo

70 Streamlining Business Process: A Case Study of Optimizing a Business Process to Issue a Letter of Assignment for a Lecturer in the University of Surabaya . . . . . . . . . . . . . 631 S.T. Jimmy

71 Design of Adventure Indonesian Folklore Game

Kartika Gunadi, Liliana and Harvey Tjahjono 
72 Measuring the Usage Level of the IE Tools in SMEs

Using Malcolm Baldrige Scoring System . . . . . . . . . . . . . . . . . . 649

I. Nyoman Sutapa, Togas W.S. Panjaitan and Jani Rahardjo

73 Enumeration and Generation Aspects of Tribonacci Strings. . . . . 659 Maukar, Asep Juarna and Djati Kerami

74 A Leukocyte Detection System Using Scale Invariant Feature Transform Method . . . . . . . . . . . . . . . . . . . . . . . 669 Lina and Budi Dharmawan

75 The Diameter of Enhanced Extended Fibonacci Cube Interconnection Networks.

Ernastuti, Mufid Nilmada and Ravi Salim

76 Prototype Design of a Realtime Monitoring System of a Fuel Tank at a Gas Station Using an Android-Based Mobile Application . . . . . . . . . . . . . . . . . . . 685 Riny Sulityowati and Bayu Bhahtra Kurnia Rafik 


\section{Introduction}

This book includes the original, peer-reviewed research papers from the 2nd International Conference on Electrical Systems, Technology and Information (ICESTI 2015), held during 9-12 September 2015, at Patra Jasa Resort \& Villas Bali, Indonesia.

The primary objective of this book is to provide references for dissemination and discussion of the topics that have been presented in the conference. This volume is unique in that it includes work related to Electrical Engineering, Technology and Information towards their sustainable development. Engineers, researchers as well as lecturers from universities and professionals in industry and government will gain valuable insights into interdisciplinary solutions in the field of Electrical Systems, Technology and Information, and its applications.

The topics of ICESTI 2015 provide a forum for accessing the most up-to-date and authoritative knowledge and the best practices in the field of Electrical Engineering, Technology and Information towards their sustainable development. The editors selected high quality papers from the conference that passed through a minimum of three reviewers, with an acceptance rate of $50.6 \%$.

In the conference there were three invited papers from keynote speakers, whose papers are also included in this book, entitled: "Computational Intelligence based Regulation of the DC bus in the On-Grid Photovoltaic System", "Virtual Prototyping of a Compliant Spindle for Robotic Deburring" and "A Concept of Multi Rough Sets Defined on Multi-Contextual Information Systems".

The conference also classified the technology innovation topics into five parts: "Technology Innovation in Robotics, Image Recognition and Computational Intelligence Applications", "Technology Innovation in Electrical Engineering, Electric Vehicle and Energy Management", "Technology Innovation in Electronic, Manufacturing, Instrumentation and Material Engineering", "Technology Innovation in Internet of Things and Its Applications" and "Technology Innovation in Information, Modeling and Mobile Applications".

In addition, we are really thankful for the contributions and for the valuable time spent in the review process by our Advisory Boards, Committee Members and Reviewers. Also, we appreciate our collaboration partners (Petra Christian 
University, Surabaya; Gunadarma University, Jakarta; UBAYA, Surabaya, University of Ciputra, Surabaya, Institute of National Technology, Malang and LNEE Springer, Germany), our supporting institution (Oulu University, Finland, Widya Mandala Catholic University, Surabaya and Dongseo University, Korea) and our sponsors (Continuing Education Centre, Petra Christian University, Surabaya and Patrajasa Resort Hotel, Bali).

On behalf of the editors

Felix Pasila 
Part II

Technology Innovation in Robotics Image

Recognition and Computational

Intelligence Applications 


\title{
Image-based Distance Change Identification by Segment Correlation
}

\author{
Nemuel Daniel Pah \\ Electrical Engineering, University of Surabaya \\ Corresponding E-mail: nemuelpah@staff.ubaya.ac.id
}

\begin{abstract}
Image-based distance identification is an interesting topic in image processing. It can be classified into three methods. The parallax approaches, the method with marker and the method with a priori knowledge of an object's physical size. The above methods are not easily implemented in an embedded system. This paper reports the development of an efficient image-based algorithm to identify the change of distance between camera and the captured object by measuring the movement of objects in the image. The algorithm is designed to work on a single camera without the aid of image markers such as laser beams. The algorithm calculates the correlation of predefined segments in the image to detect object movements, and therefore identify the direction and magnitude of distance change. The algorithm was designed to be implemented in a quadcopter to identify its change of altitude. The performance of the algorithm was examined using a simulated environment, and is reported in this paper.
\end{abstract}

Keywords: Image processing, Distance measurement, Segment Correlation

\section{Introduction}

The research that is reported in this paper was conducted to develop image-based algorithm that is able to sense the change of distance between a camera and the captured object. The algorithm was developed to be applied in a quadcopter as a sensor to provide information about altitude change to its controller.

The algorithm of image-based distance measurement system can be grouped into three main methods. The parallax method [1-3] uses two cameras or a combination of mirrors to capture two or more images from different perspectives. The second method measures object distance with an aid of markers. Barreto [4] and Muljowidodo [5] developed distance measurement algorithm based on triangulation of a single laser beam, while Deng [6] and $\mathrm{Lu}$ [7] used two parallel laser beams projected to the object. The other methods [8-9] based their calculation on the knowledge of the physical size of objects in image. Such requirements are not easily implemented in a quadcopter due to its limitation in weight and computa- 
tional capability. In [10], the author reported an algorithm to identify distance (altitude) change by observing the shift of gray level function in ten preselected rows in the image. The algorithm was able to identify distance change with an accuracy of more than $96 \%$ but with a success rate of only $76 \%$.

This paper reports the development of another efficient image-based algorithm to identify the change of distance by calculating the correlation of predefined segments in the image to identify object's movement near the left and right edges of the image's frame. The current development of the algorithm reported in this paper shows a promising result. The algorithm can identify altitude change with an accuracy of above $97 \%$.

\section{The Proposed Algorithm for Distance Change Identification}

This section elaborates the proposed image-based algorithm to identify distance change between a camera and the captured object. The algorithm is based on image frames captured from a single facing down camera, mounted on the body of a quadcopter. The algorithm is designed to be simple and efficient in terms of computational complexity, computational time, and memory usage.

The fundamental principle of the algorithm is to detect the movement of objects in the captured frames. It is assumed that objects in the image move to the edge of the frame if the camera gets closer to the ground, and vice versa.

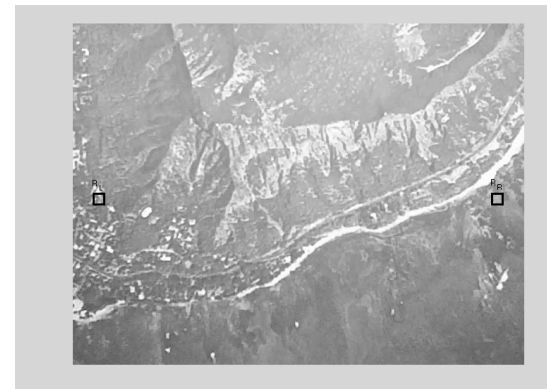

(a)

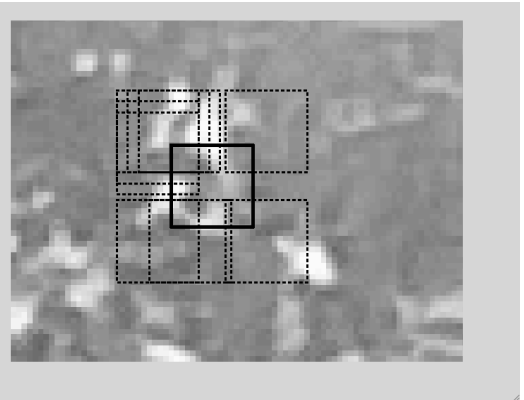

(b)

Fig. 1. (a) The boxes, $R_{L}$ and $R_{R}$, indicate the location of the referenced segments. (b) An Illustration of some neighboring segments, $R_{L}^{\prime}$, in the comparing frame, $I^{\prime}(x, y)$

\subsection{Preprocessing}

The algorithm calculates object's movement by comparing images of two consecutive frames, i.e. the reference frame, $I(x, y)$, and the comparing frame, $I^{\prime}(x, y)$. The 
image frames are grayscale image captured from an 8-bit RGB camera (460 x 640 pixels at $30 \mathrm{fps}$ ).

The algorithm only calculates the movement of objects inside two selected segments located near the left and right edges of the image frame, where object movements due to distance change are more observable. The segments, $R_{L}$ and $R_{R}$, are sub-images of the reference frame, $I(x, y)$, with a size of $15 \times 15$ pixels, as illustrated in Fig. 1a.

$R_{L}(m, n)=\{I(37+r, 247+s) \mid-7 \leq r \leq 7$ and $-7 \leq s \leq 7\}$

$R_{R}(m, n)=\{I(602+r, 247+s) \mid-7 \leq r \leq 7$ and $-7 \leq s \leq 7\}$

\subsection{Object Movement Identification}

The direction and magnitude of object's movement is calculated by searching the relative location of $R_{L}$ and $R_{R}$ in the comparing image frame, $I^{\prime}(x, y)$. The search is performed by calculating the correlation function between the reference segment $\left(R_{L}\right.$ or $\left.R_{R}\right)$ and its neighboring segments, $R_{R}^{\prime}$ or $R_{L}^{\prime}$, in the comparing frame, $I^{\prime}(x, y)$.

$C_{L}(i, j)=<R_{L}, R_{L i, j}^{\prime}>$ and $C_{R}(i, j)=<R_{R}, R_{R i, j}^{\prime}>$

The algorithm uses 400 neighboring segments on each side. The neighboring segments are the overlapping segments around the location of $R_{R}$ or $R_{L}$ with a size of $15 \times 15$ pixels (as shown in Fig. 1b). The segments are expressed with:

$R_{L}^{\prime}(m, n)_{i, j}=\left\{I^{\prime}(x+i, y+j) \mid i=20: 40\right.$, and $\left.j=230: 250\right\}$

$R_{R}^{\prime}(m, n)_{i, j}=\left\{I^{\prime}(x+i, y+j) \mid i=585: 605\right.$, and $\left.j=230: 250\right\}$

The movement vector is the vector from the centroid of $R_{R}$ or $R_{L}$ to the centroid of the local maxima in $C_{L}(i, j)$ or $C_{R}(i, j)$. By assuming that the centroid of $R_{R}$ or $R_{L}$ is at the origin, the movement vector is defined by:

$\boldsymbol{v}_{R}=\arg \max _{i, j} C_{R}(i, j)$ and $\boldsymbol{v}_{L}=\arg \max _{i, j} C_{L}(i, j)$

\subsection{Distance Change Identification}

The altitude change is identified by analyzing the two movement vectors, $v_{L}$ and $\boldsymbol{v}_{R}$. The direction of the vectors may indicate four basic movements of the camera, as illustrated in Fig. 2. 


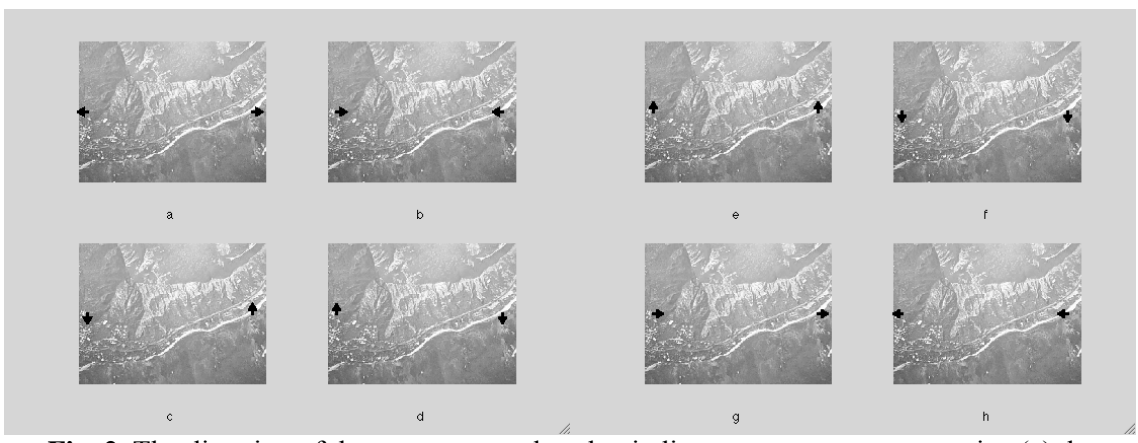

Fig. 2. The direction of the vectors $\boldsymbol{v}_{L}$ and $\boldsymbol{v}_{R}$ that indicates camera movement, i.e. (a) decrement of distance, (b) increment of distance, (c) clockwise rotation, (d) anti-clockwise rotation,

(e) downward, (f) upward, (g) left, and (h) right.

To identify the direction and amount of distance change, the algorithm calculates only the projection of the vectors along the $\mathrm{x}$-axis, $\boldsymbol{v}_{L x}$ and $\boldsymbol{v}_{R x}$. The distance increases if both vectors are pointing inward, vice versa. The amount of change, $d$, is proportional to the average of the two vectors. The distance change is considered to be absent if both vectors are pointing to the same direction, or having zero magnitude. The proportional coefficient, $k$, is determined by the initial altitude, $h$, and the horizontal size of the image frame ( 640 pixels).

$d=k \frac{v_{L x}+v_{R x}}{2} \quad$ with $\quad k=\frac{2 h}{640}$

If the initial altitude, $h$, is unknown, the change of distance, $d$, is expressed as the proportion or percentage of $h$.

The algorithm is designed to be simple in terms of computational complexity, computational time, and memory usage. The complexity of the algorithm is due to the correlation function, $\mathrm{O}\left(\mathrm{N}^{2}\right)$. However, the algorithm consumes a relatively large memory space. In total, the algorithm needs almost 3 kbytes of memory space.

\section{Experimental Results and Discussions}

The algorithm was examined using a simulated environment as that in [10]. The images were captured using LiveCam VX-800, 8-bit RGB web camera with a resolution of $480 \times 640$ pixels. The camera was mounted on a moveable platform that was able to simulate some movements of the quadcopter. The simulated movements were the change of altitude (representing change of distance) along the zaxis, rotation of camera while maintaining its distance, and horizontal translation to both the $\mathrm{x}$-axis and y-axis. A poster of aerial view was placed in front of the camera at a predetermined distance (altitude) to simulate ground view. 


\subsection{Experiments with Various Change of Distance}

In the first experiment, 20 frames were recorded from the camera at various different distances (z-axis) that represent distance changes from $+/-0.00$ meters to $+/-0.04$ meters. The frames were recorded while maintaining the camera rotation and translation. The first frame was recorded at an altitude of $h=0.70$ meters. The experiment was conducted to investigate the ability of the algorithm to identify the change of distance. The results are shown in Fig. 3.

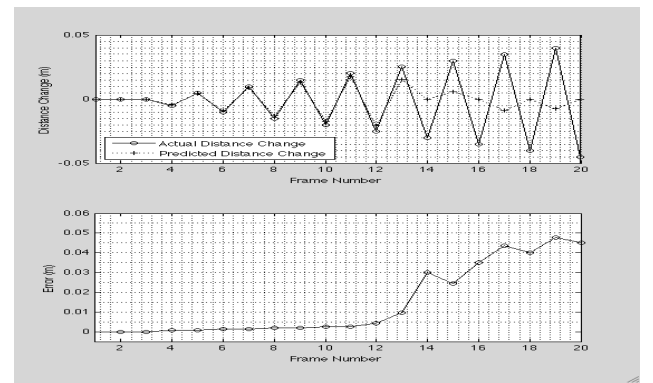

Fig. 3. The predicted distance change and error of experiment with variation of distance.

The results show that the algorithm could predict distance change accurately (with an error below 0.005 meters) from frame 1 to frame 11 when the distance change was below 0.02 meters. As the distance change was increased to a value above 0.02 meters, the algorithm failed to identify this change. The error increased to an unacceptable rate.

The limitation of the algorithm was caused by the distribution of the neighboring searching segments as explained in Section 2.2. The algorithm is only sensitive to a distance change of up to 0.0219 meters (equivalent to $3.12 \%$ of its original distance).

\subsection{Experiments with Translational Movement}

The second experiment was conducted to investigate the algorithm's ability to compensate horizontal translation to both $\mathrm{x}$-axis and $\mathrm{y}$-axis. In the experiment, 25 frames were recorded from the camera at a constant altitude (z-axis) of 0.60 meters, while translated along the $\mathrm{x}$-axis and $\mathrm{y}$-axis as shown in Table 1 . The results, shown in Fig. 4, confirm that the algorithm was able to compensate the translational movement with the maximum error of less than 0.01 meters (equivalent to $1.67 \%$ of the initial distance). The error was due to the algorithm's misinterpretation of other objects as if it was the shift of the original object in $R_{R}$ or $R_{L}$. The misinterpretation may occur if the captured images consist of flat, monotone, or periodic texture. 


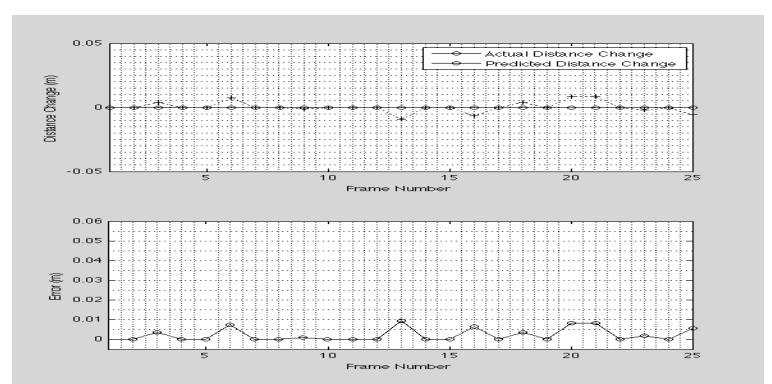

Fig. 4. The predicted distance change and error of experiment with translational movement.

Table 1. The x-axis and y-axis (in $\mathrm{cm}$ ) translations of the frames in Fig. 5.

\begin{tabular}{cccccccccccccc}
\hline Frame & $\mathbf{1}$ & $\mathbf{2}$ & $\mathbf{3}$ & $\mathbf{4}$ & $\mathbf{5}$ & $\mathbf{6}$ & $\mathbf{7}$ & $\mathbf{8}$ & $\mathbf{9}$ & $\mathbf{1 0}$ & $\mathbf{1 1}$ & $\mathbf{1 2}$ & $\mathbf{1 3}$ \\
\hline x-axis & 0.0 & 0.0 & 0.5 & 1.0 & 1.5 & 2.0 & 2.0 & 1.5 & 1.0 & 0.5 & 0.0 & -0.5 & -1.0 \\
y-axis & 0.0 & 0.0 & 0.0 & 0.0 & 0.0 & 0.0 & 0.0 & 0.0 & 0.0 & 0.0 & 0.0 & 0.0 & 0.0 \\
\hline \multicolumn{10}{r}{} & \multicolumn{10}{c}{} & $\mathbf{1 5}$ & $\mathbf{1 6}$ & $\mathbf{1 7}$ & $\mathbf{1 8}$ & $\mathbf{1 9}$ & $\mathbf{2 0}$ & $\mathbf{2 1}$ & $\mathbf{2 2}$ & $\mathbf{2 3}$ & $\mathbf{2 4}$ & $\mathbf{2 5}$ \\
\hline Frame & $\mathbf{1 4}$ & $\mathbf{1 5}$ & -1.5 & -1.0 & -0.5 & 0.0 & 0.0 & 0.0 & 0.0 & 0.0 & 0.0 \\
\hline x-axis & -1.5 & -2.0 & -2.0 & -1.0 & \\
y-axis & 0.0 & 0.0 & 0.0 & 0.0 & 0.0 & 0.0 & 0.0 & 1.0 & 2.0 & 0.0 & -1.0 & -2.0 \\
\hline
\end{tabular}

\subsection{Experiments with Rotational Movement}

This experiment was conducted to investigate the algorithm's ability to compensate rotation movement. In this experiment, 9 frames were recorded from the camera at a constant altitude (z-axis) of 0.50 meters, while rotating around z-axis. The results, shown in Fig. 5, confirm that the algorithm was able to compensate the rotational movement with the maximum error of less than 0.015 meters (equivalent to $3 \%$ of the initial distance). The error was also due to the algorithm's misinterpretation of other object as if it was the shift of the original object in $R_{R}$ or $R_{L}$. As with the translational case, the misinterpretation may occur if the captured images consist of flat, monotone, or periodic texture.

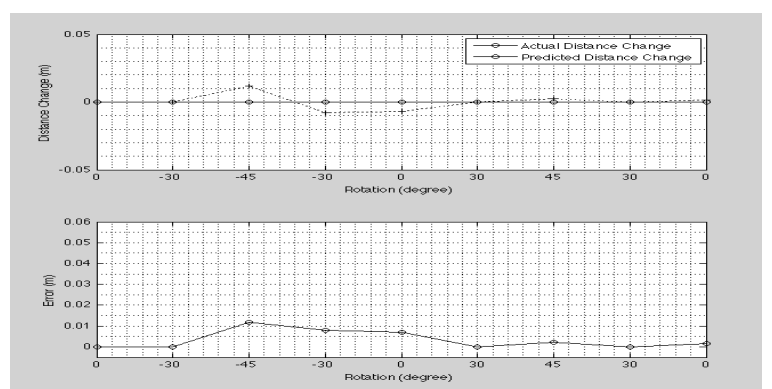

Fig. 5. The predicted distance change and error of experiment with rotational movement. 


\section{Conclusion}

This paper presents an image-based algorithm to identify the change of distance based on correlation of reference segments. The algorithm was able to identify distance change of up to $3.12 \%$ of its initial distance with an accuracy of more than $97 \%$, and is able to compensate horizontal and rotational movement. The future suggested development of the algorithm would be the simplification of computational complexity from $\mathrm{O}\left(\mathrm{N}^{2}\right)$ to $\mathrm{O}(\mathrm{N})$, the approach to reduce the number of needed memory, and the improvement of the algorithm accuracy.

\section{Reference citations}

[1] L. Y. Deng, N. C. Tang, T. K. Shih, D.-L. Lee, Y.-H. Cheng, and K.-Y. Lo, "The Development of Image-based Distance Measurement System," J. Internet Technol., vol. 10, no. 1, 2009.

[2] H. Kim, C. Lin, J. Song, and H. Chae, "Distance Measurement Using a Single Camera with a Rotating Mirror,” Int. J. Control. Autom. Syst., vol. 3, no. 4, pp. 542-551, 2005.

[3] T. Hsu and T. Wang, "An Improvement Stereo Vision Images Processing for Object Distance Measurement," 2013.

[4] S. V. F. Barreto, R. E. Sant'Anna, and M. Feitosa, "A Method for Image Processing and Distance Measuring Based on Laser Distance Triangulation," in IEEE 20th International Conference on Electronics, Circuits, and Systems (ICECS), 2013 Page(s): 695 - 698, pp. 695 - 698.

[5] K. Muljowidodo, Mochhammad A. Rasid, and A. Budiyono, "Distance Measurement, Laser Spot Identification, Innovative Measuring System," Indian J. Mar. Sci., vol. 38, no. 3, pp. 324-331, 2009.

[6] L. Y. Deng, N. C. Tang, T. K. Shih, D.-L. Lee, Y.-H. Cheng, and K.-Y. Lo, "The Development of Image-based Distance Measurement System," J. Internet Technol., vol. 10, no. 1, 2009.

[7] M.-C. Lu, W.-Y. Wang, and C.-Y. Chu, "Image-Based Distance and Area Measuring Systems,” IEEE Sens. J., vol. 6, no. 2, pp. 495-503, 2006.

[8] M. P. D. Deshmukh and P. G. P. Dhok, "Analysis Of Distance Measurement System Of Leading Vehicle,” Int. J. Instrum. Control Syst., vol. 2, no. 1, pp. 11-23, 2012.

[9] A. Rahman, A. Salam, M. Islam, and P. Sarker, “An Image Based Approach to Compute Object Distance," Int. J. Comput. Intell. Syst., vol. 1, no. 4, pp. 304-312, 2008.

[10] N. D. Pah and H. Hermawan, "The Development of Image-based Algorithm to Identify Altitude Change of a Quadcopter," accepted to be presented in The $7^{\text {th }}$ International Conference on Information Technology and Electrical Engineering (ICITEE), 2015. 

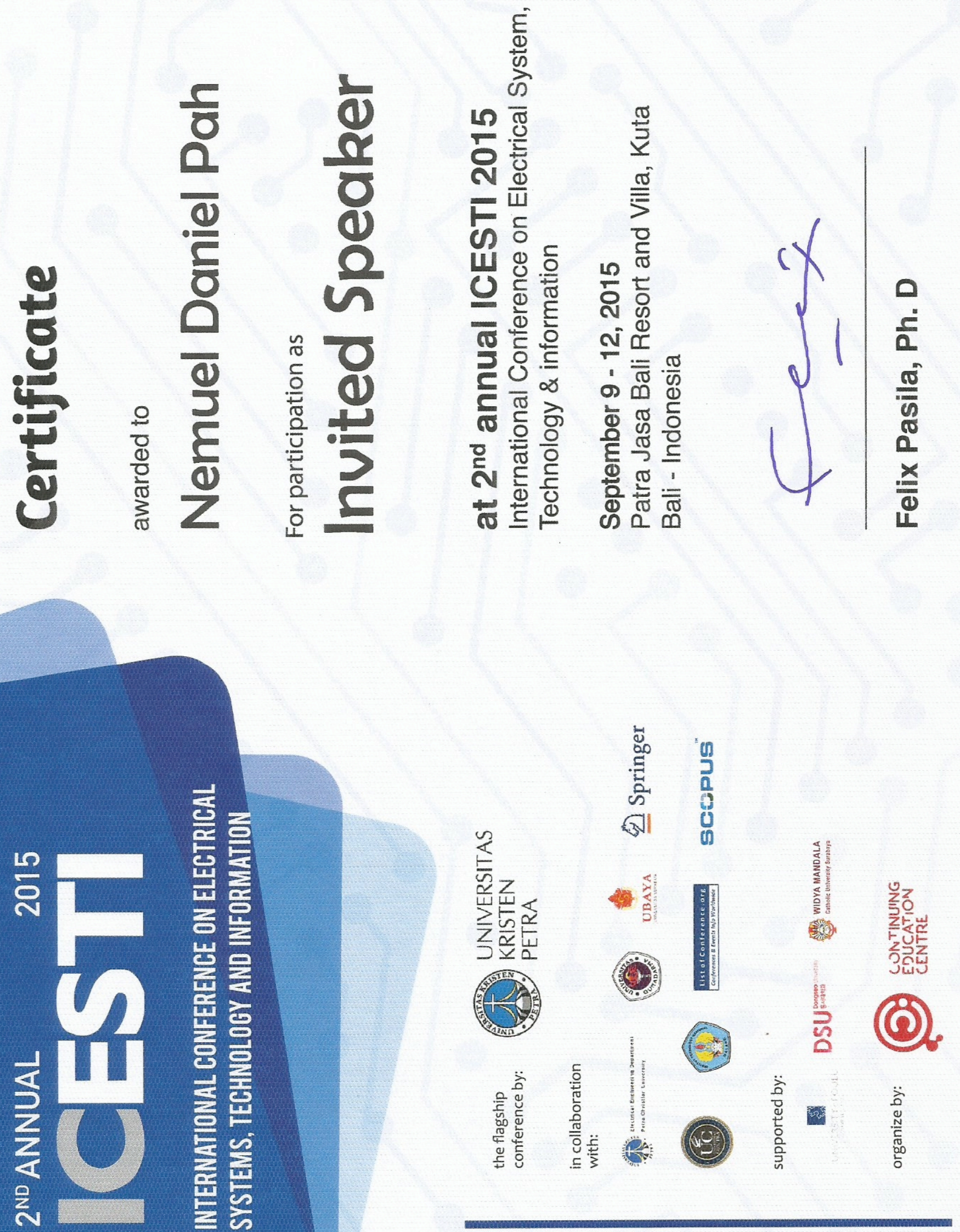